\title{
Cloning, Characterization and Antifungal Activity of Defensin Tfgd1 from Trigonella foenum-graecum $\mathrm{L}$.
}

\author{
Sudar Olli and P. B. Kirti* \\ Department of Plant Sciences, School of Life Sciences, University of Hyderabad, Hyderabad, 500046, India
}

Received 21 July 2005, Accepted 30 January 2006

\begin{abstract}
Defensins are small cysteine rich peptides with a molecular mass of 5-10 kDa and some of them exhibit potent antifungal activity. We have cloned the coding region of a cDNA of 225 bp cysteine rich defensin, named as $T f g d 1$, from the legume Trigonella foenum-graecum. The amino acid sequence deduced from the coding region comprised 74 amino acids, of which the N-terminal 27 amino acids constituted the signal peptide and the mature peptide comprised 47 amino acids. The protein is characterized by the presence of eight cysteine resisdues, conserved in the various plant defensins forming four disulphide bridges, which stabilize the mature peptide. The recombinant protein expressed in $E$ coli exhibited antifungal activity against the broad host range fungus, Rhizoctonia solani and the peanut leaf spot fungus, Phaeoisariopsis personata.
\end{abstract}

Keywords: Antifungal activity, Defensin, Tfgd1, Trigonella foenum-graecum

\section{Introduction}

Plant defensins are a family of highly stable basic proteins of 45-54 amino acids containing eight cysteine residues that form disulfide bridges (Broekaert et al., 1995). Members of this family have been characterized in several plant species at both the DNA and protein level from various plant tissues, including leaves, pods, tubers, fruits and flowers (Broekaert et al., 1997; Lay et al, 2003). Much of the work, however, has been performed on seeds where these proteins are prevalent (Osborn et al., 1995). All plant defensins share a characteristic three-dimensional folding pattern, stabilized by four disulfide bridges (Broekaert et al., 1995), which incorporates the cysteine-stabilized $\alpha \beta(\mathrm{CS} \alpha \beta)^{1}$ motif (Cornet et al., 1995).

* To whom correspondence should be addressed.

Tel: 91-40- 23134545; Fax: 91-40-23010120

E-mail: pbksl@uohyd.ernet.in
The three-dimensional structure is dominated by a triple stranded, antiparallel $\beta$-sheet and a single $\alpha$-helix lying in parallel with the $\beta$-sheet (Bruix et al., 1993). However, it has been reported recently that defensin from Petunia hybrida, PhD1 has five disulfide bonds (Bert et al., 2003). It appears that the fifth disulfide bond, which is adjacent to the hydrogen bond between the conserved threonine and glutamic acid residues of the other plant defensins, sufficiently stabilizes the protein to make part of the hydrogen bond network dispensable, thereby playing an intricate role in the stabilization of the protein in a manner that is complementary to those of other plant defensins.

Some plant defensins exhibit antifungal activity, although it is not known whether they have a common mode of action (Broekaert et al., 1997). One of the best-characterized antifungal plant defensins, Rs-AFP2 from radish (Raphanus sativus) seed appears to act primarily at the cell membrane (Thevissen et al., 1996). Rs-AFP2 induces rapid $\mathrm{Ca}^{2+}$ uptake and $\mathrm{K}^{+}$efflux from Neurospora crassa hyphae and thus may inhibit the growth of filamentous fungi by disrupting cytosolic $\mathrm{Ca}^{2+}$ gradients essential for hyphal tip growth(Thevissen et al., 1996). Thevissen and colleagues (2000) have proposed a model for the mode of action of plant defensins, in which membrane patches containing $\mathrm{M}(\mathrm{IP})_{2} \mathrm{C}$ constitute binding sites for DmAMP1 or, alternatively, are required for anchoring of membrane or cell-wall-associated proteins, which themselves interact with DmAMP1. In addition, it has been recently reported that structurally homologous antifungal peptides present in species from different eukaryotes interact with the same target in the fungal plasma membrane, namely glucosylceramides (Thevissen et al., 2004). Spelbrink et al. (2004) demonstrated that both MsDef1 and the $\mathrm{Ca}^{2+}$ channel blocker, EGTA suppressed the growth of fungal hyphae and induced their hyperbranching. This indicates that defensins retard hyphal growth by affecting a $\mathrm{Ca}^{2+}$ transport. However, this finding cannot be applicable to all plant defensins as RsAFP2 shows antifungal activity without blocking effect on any of the $\mathrm{Ca}^{2+}$ channels (Spelbrink et al., 2004). Moreover, MsDef1 and RsAFP2 resemble each other in three- 
dimensional structure and yet are distinct in primary amino acid sequence (Fant et al., 1998). This indicates dissimilar modes of action for these two structurally related defensins. Certain members within the plant defensin family also display other biological activities, including proteinase (Wijaya et al., 2000; Melo et al., 2002) and $\alpha$-amylase inhibitory activity (Bloch and Richardson, 1991; Zhang et al., 1997) and inhibition of protein translation (Collila et al., 1990; Mendez et al., 1990, 1996) that may contribute to their role in defense.

It has been shown that the transgenic expression of plant defensin leads to the protection of vegetative tissues against pathogen attack. Constitutive expression of a radish defensin clearly enhanced resistance of tobacco plants to the fungal leaf pathogen Alternaria longipes (Terras et al., 1995) and similarly in tomato to Alternaria solani (Parashina et al., 2000). Canola (Brassica napus) constitutively expressing a pea defensin showed enhanced resistance against blackleg (Leptosphaeria maculans) disease (Wang et al., 1999). It was also shown that constitutive expression of an alfalfa defensin in potato provided robust resistance against the agronomically important fungus Verticillium dahliae under field conditions (Gao et al., 2000).

We have cloned a new legume defensin from Trigonella foenum-graecum L. (Tfgd1) and its in vitro antifungal activity has been checked through prokaryotic expression of the recombinant protein. Our observations on the newly cloned defensin are presented in this communication.

\section{Materials and Methods}

Basic molecular studies. Total RNA was extracted from the leaf tissue from ten-day old seedlings after treatment with $30 \mu \mathrm{M}$ methyl jasmonate for $24 \mathrm{~h}$, using Tri-Reagent (SIGMA) following the manufacturer's instructions. The final RNA pellet was dissolved in formamide.

Basic molecular biology techniques were derived from Sambrook et al., 1989. The isolated RNAs were reverse transcribed at $42^{\circ} \mathrm{C}$ for 60 minutes using 200 units of M-MuLV reverse transcriptase (New England Biolabs) in a $50 \mu \mathrm{L}$ reaction mixture containing reverse transcriptase buffer, dNTPs and reverse primer of defensins as per the manufacturer's instructions. Five $\mu \mathrm{L}$ of the resultant first-strand cDNA was amplified with a pair of specific oligonucleotide primers for defensin coding region viz., forward primer: 5'GGGTACCATGGAGAAGAAATCACTAGC3' and the reverse primer: 5'GGGATCCTTAACATCTTTTAGTACACCA3' in a $50 \mu \mathrm{L}$ reaction mixture (Gibco BRL PCR buffer, $200 \mu \mathrm{M}$ dNTP, 20 pmoles of each primer). Restriction enzyme sites of $K p n I$ and BamHI were included in the forward and reverse primers respectively to facilitate cloning of the amplification product in future cloning steps. The amplification conditions were, $4 \mathrm{~min}$ at $94^{\circ} \mathrm{C}$ for initial denaturation, $45 \mathrm{~s}$ at $55^{\circ} \mathrm{C}$ for annealing, $2 \mathrm{~min}$ at $72^{\circ} \mathrm{C}$ for extension and $10 \mathrm{~min}$ for final extension. The amplifed product was electrophoresed on a $1 \%$ agarose gel, the amplified fragment of interest was cut out from the gel and DNA was eluted from the gel slice using the Gel elution kit as per the manufacturer's instructions (Eppendorf). The eluted product was cloned into a TA cloning vector, pTZ57R (MBI Fermentas). The clones were sequenced commercially, and their nucleotide and amino acid sequence comparisons were done using the Basic Local Alignment Search Tool (BLAST) on the non-redundant data bank of the National Center for Biotechnology Information (NCBI) (http:// www.ncbi. nlm.nih.gov/BLAST/). Expasy tool was used to deduce the amino acid sequence of the new defensin.

In vitro expression studies: Construction of the expression plasmid. The $225 \mathrm{bp}$ fragment encoding $T f g d 1$ was isolated from Tfgd1/pTZ57R-T plasmid by digestion with KpnI and BamHI and ligated into the KpnI/BamHI- digested pET32a in frame to the T7 promoter, His tag and $\mathrm{S}$ tag. E.coli $\mathrm{DH} 5-\alpha$ was transformed using the resultant plasmid (rTfgd1/pET32a). The event of cloning of $T f g d 1$ into the expression vector was confirmed by purifying the plasmid and digesting it with KpnI and BamHI. This plasmid was then transformed into $E$. coli BL21 (DE3) pLysS cells for protein purification.

Overexpression and purification of recombinant Tfgd1. An overnight pre-culture of $E$. coli BL21 (DE3) pLysS containing the rTfgd1/pET32a was used to inoculate $4 \times 500 \mathrm{ml}$ flasks of LB containing $50 \mathrm{mg} / \mathrm{ml}$ ampicillin and $35 \mathrm{mg} / \mathrm{ml}$ chloramphenicol, and cultures were allowed to grow with shaking at $37^{\circ} \mathrm{C}$ and 200 rpm until an optical density of 0.6 to $0.8\left(\mathrm{OD}_{600} \mathrm{~nm}\right)$ was reached. Protein production was induced by adding $1 \mathrm{mM}$ IPTG to the cell culture, and the cells were shaken at $37^{\circ} \mathrm{C}$ for an additional 5-6 h. The cells (typically $2 \mathrm{~g}$ of wet cells) were harvested by centrifugation (15 min at 10,000 g), washed twice with 1X PBS pH 7.4 and were resuspended in $5 \mathrm{ml}$ of ice-cold lysis buffer $(10 \mathrm{mM}$ Tris, $300 \mathrm{mM}$ $\mathrm{NaCl}, 10 \mathrm{mM}$ imidazole and protease inhibitors mix (Novagen). Lysozyme $(1 \mathrm{mg} / \mathrm{ml})$ was added to the cell suspension and incubated for $30 \mathrm{~min}$ on ice. Further, Triton X-100 (1\%) was added and continued incubation with rocking for another $10 \mathrm{~min}$ at $4^{\circ} \mathrm{C}$. The cells were then sonicated at $12 \mathrm{~Hz} \times 3 / 2 \mathrm{~min}$ interval. The supernatant was collected by centrifugation at $10,000 \mathrm{rpm}$ for 30 $\min$ at $4^{\circ} \mathrm{C}$. The cleared supernatant was loaded on to a $5 \mathrm{ml} \mathrm{Ni}$ NTA His-Bind resin column, which was equilibrated with the binding buffer $(20 \mathrm{mM}$ Tris, $300 \mathrm{mM} \mathrm{NaCl}, 10 \mathrm{mM}$ imidazole, $10 \%$ glycerol, $0.1 \%$ Triton X-100 and protease inhibitors mix). The column was washed with 5 volumes of binding buffer followed by 10 volumes of wash buffer $(20 \mathrm{mM}$ Tris, $300 \mathrm{mM} \mathrm{NaCl}, 20 \mathrm{mM}$ imidazole, $10 \%$ glycerol and $0.1 \%$ Triton X-100). Finally, the His6tagged and $\mathrm{S}$ tagged Tfgd1 was eluted from the column with the elution buffer ( $20 \mathrm{mM}$ Tris, $500 \mathrm{mM} \mathrm{NaCl}, 200 \mathrm{mM}$ imidazole). In each case $0.5 \mathrm{ml}$ fractions were collected and the purification profile was checked on a $18 \%$ SDS-PAGE (Laemmli, 1970) and by western blot using anti His-Tag immunoglobulin. HRP conjugated goat anti-mouse IgG was obtained from Bangalore genei.

Gel filtration chromatography. Gel filtration chromatography was performed on a Sephadex G-50 column with a flow rate of $1 \mathrm{ml} /$ min, according to manufacturer's instructions. The column equilibration and sample preparation was done using $50 \mathrm{mM}$ Tris $\mathrm{pH}$ 7.4, containing $150 \mathrm{mM} \mathrm{NaCl}$. Fractions of $0.5 \mathrm{ml}$ were collected and O.D at $\mathrm{A}_{280}$ was measured. Further, purity of the fractions was checked by SDS-PAGE. The protein concentration was determined using Lowry method and the protein was used in the antifungal assay. 
Antifungal assay: Activity against Rhizoctonia solani. Standard assays were carried out in Petri dishes containing about $20 \mathrm{ml}$ of potato dextrose agar. For the assay a piece of agar containing frontal mycelia of Rhizoctonia solani was placed in the center of the plate. The plates were incubated for $6 \mathrm{~h}$ at $24^{\circ} \mathrm{C}$. After this first incubation period, sterile paper discs (3 MM, Whatman) were placed at a distance of $0.5 \mathrm{~cm}$ around the frontal mycelia. Different concentrations of the protein sample were added to each disk. The plates were incubated at $24^{\circ} \mathrm{C}$ for approximately $36 \mathrm{~h}$ until mycelial growth had enveloped peripheral discs containing control buffer and had formed crescent of inhibition around the disc containing an effective concentration of antifungal agent. For the assay different concentration of the protein were spotted on discs. The extraction buffer (50 mM Tris, pH 7.4, $150 \mathrm{mM} \mathrm{NaCl}$ ) was used as a control.
Antifungal activity of $\boldsymbol{T f g d} \mathbf{1}$ against Phaeoisariopsis personata. The concentration of the Phaeoisariopsis personata spore inoculum taken was 50,000 conidia/ml. Equal amount of the inoculum was added to both the glass slides containing control [Extraction buffer (50 mM Tris, $\mathrm{pH} 7.4,150 \mathrm{mM} \mathrm{NaCl}$ )] and the test sample, Tfgd1 ( $100 \mu \mathrm{g}$ concentration). The slides were then incubated at $25^{\circ} \mathrm{C}$ in a moist chamber and observations on spore germination were made after $24 \mathrm{~h}, 48 \mathrm{~h}$ and $72 \mathrm{~h}$.

\section{Results and Discussion}

cDNA cloning and sequencing. The coding region of the defensin cDNA from $T$. foenum graecum (Tfgd1: AY182163)

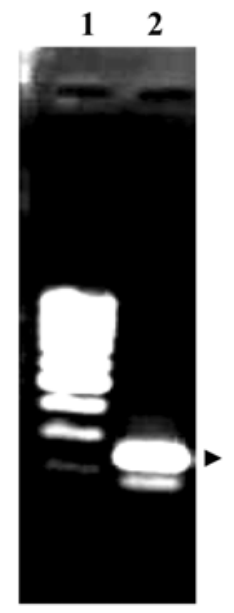

(a)

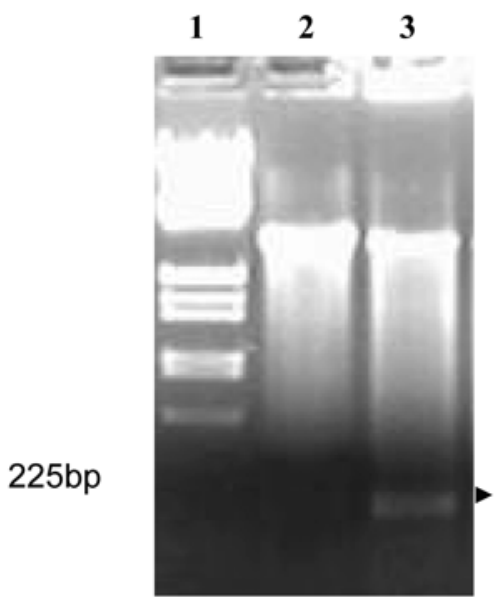

(b)

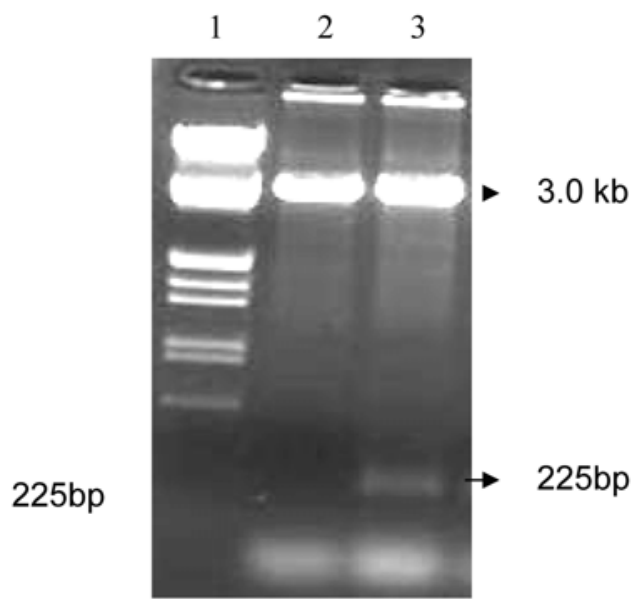

(c)

Fig. 1. Agarose Gel showing cloning of the RT-PCR amplified fragment of $T f g d 1$ from Trigonella foenum-graecum. into pTZ57R sequencing vector and pET 32-a expression vector. The amplification was carried out using PDF and PDR primers. The leaf material in each case was collected after methyl jasmonate treatment. (a) The different lanes are: 1) $100 \mathrm{bp}$ DNA ladder, 2) Trigonella foenumgraecum (Tfgd1). (b) The different lanes are: 1. $\lambda$ DNA/EcoRI + HindIII marker, 2. pTZ57R vector cut with KpnI and BamHI, 3. Tfgd1 cut with KpnI and BamHI. (c) The different lanes are: 1. $\lambda$ DNA/EcoRI + HindIII marker, 2. pET 32a vector cut with KpnI and BamH I, 3. Tfgd1 cut with KpnI and BamHI.

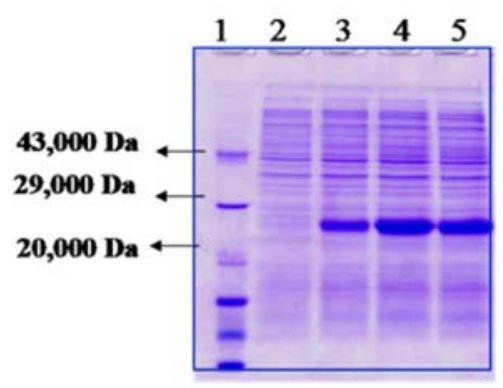

(a)

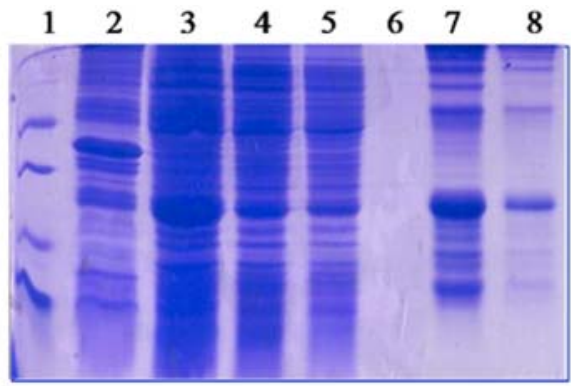

(b)

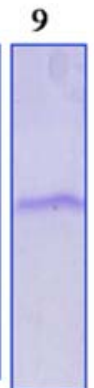

(c)

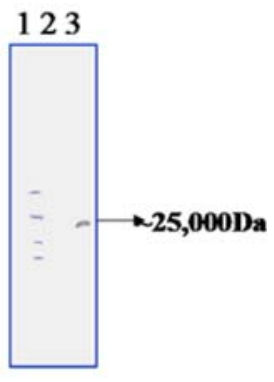

(d)

Fig. 2. SDS-PAGE and Western blot showing IPTG induced recombinant protein and purification profile of Tfgd1. SDS-PAGE showing the induction of Tfgd1 using IPTG. The different lanes are: 1. Low range marker, 2. - IPTG, $3.1 \mathrm{~h}$ after IPTG induction, $4.3 \mathrm{~h}$ after IPTG induction, 5. $5 \mathrm{~h}$ after IPTG induction. SDS-PAGE showing the partial purification profile of Tfgd1 using Ni-NTA His Bind Resin. The different lanes are: 1. Low range marker, 2. Crude extract, 3. Flow through, 4. Wash 1, 5. Wash 20, 6. Elution I, 7. Elution II. SDS-PAGE showing the purified Tfgd1 using Sephadex G-50 column. Western Blot showing the purified Tfgd1. The blot was probed with anti His Tag IgG 


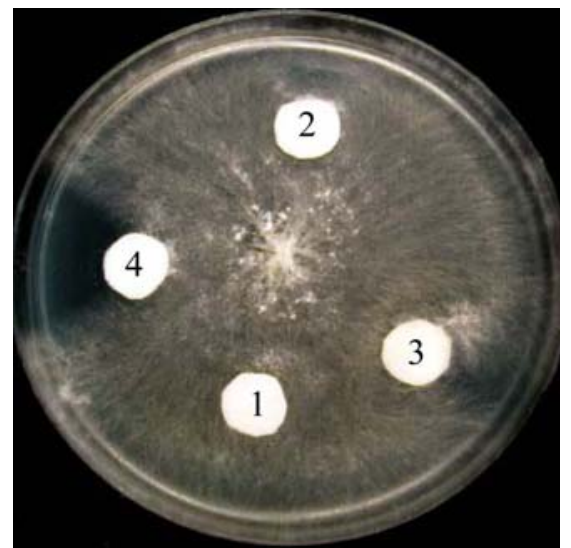

Fig. 3. In vitro antifungal assay of Tfgd 1 showing inhibition of the mycelial growth of the broad host range fungus, Rhizoctonia solani. Disc 1. Control [Extraction buffer $(50 \mathrm{mM}$ Tris $\mathrm{pH} 7.5$, $150 \mathrm{mM} \mathrm{NaCl}$ )], Disc 2. $20 \mu \mathrm{g}$ of Tfgd1, Disc 3. $50 \mu \mathrm{g}$ of Tfgd1, Disc 4. $100 \mu \mathrm{g}$ of Tfgd1.

was cloned using RT-PCR on RNA extracted from the leaves, after treatment with methyl jasmonate, since methyl jasmonate has been reported to induce high-level expression of plant defensins (Penninckx et al., 1998). The coding region of Tfgd 1 is of $225 \mathrm{bp}$ length (Fig. 1a and 1b). As no amplification was observed in RNA from untreated leaves in RT-PCR reaction and the same was observed in RNA preparations from leaves upon treatment with methyl jasmonate, further expression studies were not carried out. The N-terminal portion of the peptide has a 27 amino acid residue long signal peptide and the mature protein has 45 amino acids in all reported defensins except in case of Tfgd1, which has 47 amino acids. The cleavage site for the signal peptide was predicted using the SignalP program (signalp@ cbs.dtu.dk). The signal peptide was shown to be a secretory type using the TargetP program (http://www.cbs.dtu.dk/ services/TargetP/).

The new defensin was amplified and cloned by using the specific primers derived from the Medicago sativa defensin (AlfAFP). The high level of sequence similarity along with the fact that the same set of primers amplified defensin cDNAs from different legume species indicate that the defensin genes in legumes appear to be highly conserved (data not shown).

In vitro expression studies. The $T f g d 1$ was cloned into the bacterial expression vector pET 32a (Fig. 1c) and the recombinant expression vector was used to transform the BL21 (DE3) pLysS cells. The recombinant protein was then over-expressed by IPTG induction as an approximately 25 $\mathrm{kDa}$ protein (Fig. 2a). The molecular mass of the new defensin is $\sim 7-8 \mathrm{kDa}$ and the size of the tag associated with the defensin, Tfgdl is $16 \mathrm{kDa}$. Therefore, the recombinant protein that we get on overexpression is approximately of the a) Control

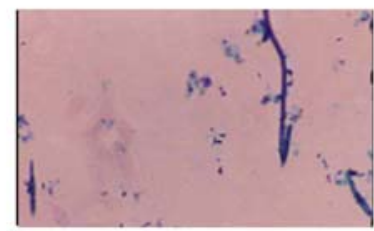

a-1) After 24 h

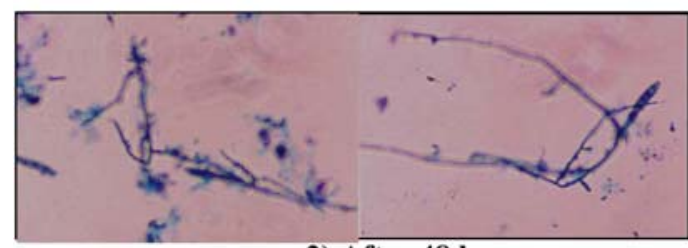

a-2) After 48 h

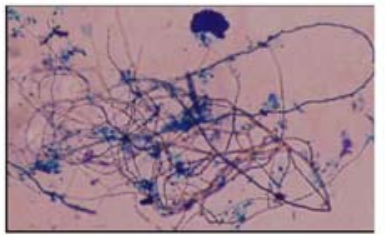

a-3) After 72 h b) Treated with Tfgd1

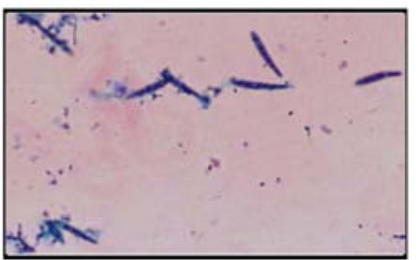

b-1) After 24 h

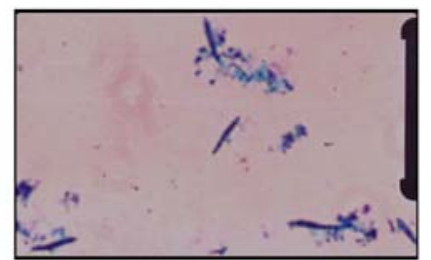

b-2) After 48 h

Fig. 4. Antifungal assay of Tfgd1 showing inhibition of the spore germination of Phaeoisariopsis personata. 4 (a) Control sample [Extraction buffer $(50 \mathrm{mM}$ Tris $\mathrm{pH} 7.5,150 \mathrm{mM} \mathrm{NaCl})]+$ spores $(50,000$ conidia/ml). 4 (a-1): Control spores after $24 \mathrm{~h}$ showing the initiation of spore germination. 4 (a-2): Control spores after $48 \mathrm{~h}$ showing the growth of the hyphae. 4 (a-3): Control spores after $72 \mathrm{~h}$ showing profuse growth of the mycelium. 4 (b): Tfgd1 $(100 \mu \mathrm{g})+$ spores $(50,000$ conidia/ml). 4 (b-1): Tfgd1 treated spores showing no germination after 24 h. 4 (b-2): Tfgd1 treated spores showing inhibition of germination even after $48 \mathrm{~h}$. 
size $25 \mathrm{kDa}$. This overexpressed protein was then partially purified using Ni-NTA His Bind resin (Fig. 2b). Further purification was achieved using gel filtration chromatography (Fig. 2c). The purified protein was confirmed by the western blot using anti His tag IgG (Fig. 2d).

Antifungal assay: Activity against Rhizoctonia solani. The possible toxicity of the purified peptide, Tfgd1 was tested using the fungus, Rhizoctonia solani. It is apparent from the Fig. 3 that the recombinant protein inhibited the mycelial spread of Rhizoctonia solani and formed a crescent of growth inhibition, whereas the extraction buffer (disc 1) had no detectable effect on the fungus. Fig. 3 clearly shows that $100 \mu \mathrm{g}$ concentration of Tfgd 1 inhibits the mycelial spread of Rhizoctonia solani and shows a crescent of growth inhibition around the disc 4 . As the concentration decreases, there was a decline in the inhibition range as observed in disc $3(50 \mu \mathrm{g})$ and disc $2(20 \mu \mathrm{g})$.

Activity against Phaeoisariopsis personata. When the recombinant protein of Tfgd1 was further tested for its activity for inhibition of germination of the spores of Pheaoisariopsis, it was observed that $100 \mu \mathrm{g}$ concentration of the protein was an inhibitory factor for spore germination and consequential hyphal growth even after $48 \mathrm{~h}$, when compared to the control treatment (Fig. 4), which evidenced spore germination and profuse growth of the hyphae, there by confirming the antifungal nature of Tfgd1 against germination of spores of Phaeoisariopsis personata. Our future approach would be to use this potent antifungal peptide in transforming plants for disease resistance.

Thus, the new defensin Tfgd1 cloned and characterized from $T$. foenum-graecum appears to possess antifungal activity and hence, is a suitable candidate for deployment in transgenic crops for deriving resistance against fungal diseases. Efforts are presently aimed at transferring this to peanut and other crops.

Acknowledgments Sudar Olli is grateful to the CSIR, Government of India for the award of a Research Fellowship. The financial assistance in the form of a Research Grant from the Andhra Pradesh-Netherlands Biotechnology Programme, Institute of Public Enterprise, Osmania University Campus, Hyderabad, India.

\section{References}

Ai-Guo, G., Hakimi, S. M., Mittnack, C. A., Yonnie, W., Woerner, M., Stark, D. M., Shah, D. M., Liang, J. and Rommens, C. M. T. (2000) Fungal pathogen protection in potato by expression of a plant defensin peptide. Nature Bio/Technology 18, 13071310.

Bert, J. C. J., Horst, J. S., Fung, T. L., Marilyn, A. A. and David, J. C. (2003) Structure of petunia hybrida defensin 1, a novel plant defensin with five disulfide bonds. Biochemistry 42,
8214-8222.

Bloch, C. Jr. and Richardson, M. (1991) A new family of small (5 $\mathrm{kDa}$ ) protein inhibitors of insect alpha-amylases from seeds or sorghum (Sorghum bicolor moench) have sequence homologies with wheat $\gamma$-purothionins. FEBS Lett. 279, 101-104.

Broekaert, W. F., Cammue, B. P. A., DeBolle, M. F. C., Thevissen, K., Desamblanx, G. W. and Osborn, R. W. (1997) Antimicrobial peptides from plants. Crit. Rev. Plant Sci. 16, 297-323.

Broekaert, W. F., Terras, F. R. G., Cammue, B. P. A. and Osborn, R. W. (1995) Plant defensins: Novel antimicrobial peptides as components of the host defense system. Plant Physiol. 108, 1353-1358.

Bruix, M. A., Jimenez, J., Santoro, C., Gonzalez, F. J., Colilla, E. and Mendez, M. R. (1993) Solution structure of gamma 1-H and gamma 1-P thionins from barley and wheat endosperm determined by 1H-NMR: a structural motif common to toxic arthropod proteins. Biochemistry 32, 715-724.

Colilla, F. J., Rocher, A. and Mendez, E. (1990) $\gamma$-purothionins: amino acid sequence of two polypeptides of a new family of thionins from wheat endosperm. FEBS Lett. 270, 191-194.

Cornet, B., Bonmatin, J. M., Hetru, C., Hoffmann, J. A., Ptak, M. and Vovelle, F. (1995) Refined three-dimensional solution structure of insect defensin A. Structure 3, 435-448.

Fant, F., Vranken, W., Broekaert, W. and Borremans, F. (1998) Determination of the three-dimensional solution structure of Raphanus sativus antifungal protein by $1 \mathrm{H}$ NMR. J. Mol. Biol. 279, 257-270.

Laemmli, U. K. (1970) Cleavage of structural protein during the assembly of the head of bacteriophage T4. Nature 227, 680685.

Lay, F. T., Schirra, H. J., Scanlon, M. J., Anderson, M. A. and Craik, D. J. (2003) The three-dimensional solution structure of $\mathrm{NaD1}$, a new floral defensin from Nicotiana alata and its application to a homology model of the crop defense protein AlfAFP. J. Mol. Biol. 325, 175-188.

Melo, F. R., Rigden, D. J., Franco, O. L., Mello, L. V., Ay, M. B., Grossi de Sa, M. F. and Bloch, C. Jr. (2002) Inhibition of trypsin by cowpea thionin: characterization, molecular modeling, and docking. Proteins Struct. Funct. Genet. 48, 311319.

Mendez, E., Moreno, A., Collila, F., Pelaez, F., Limas, G. G., Mendez, R., Soriano, F., Sainas, M. and DeHaro, C. (1990) Primary structure and inhibition of protein synthesis in eukaryotic cell-free system of a novel thionin, $\gamma$-hordothionin, from barley endosperm. Eur. J. Biochem. 194, 533-539.

Mendez, E., Rocher, A., Calero, M., Girbes, T., Citores, L. and Soriano, F. (1996) Primary structure of $\omega$-hordothionin, a novel member of a family of thionins from barley endosperm, and its inhibition of protein synthesis in eukaryotic and prokaryotic cell-free systems. J. Biochem. 239, 67-73.

Osborn, R. W., De Samblanx, G. W., Thevissen, K., Goderis, I., Torrekens, S., Van Leuven, F., Attenborough, S., Rees, S. B. and Broekaert, W. F. (1995) Isolation and characterization of plant defensins from seeds of Asteraceae, Fabaceae, Hippocastanaceae and Saxifragaceae. FEBS Lett. 368, 257262.

Parashina, E. V., Serdobinskii, L. A., Kalle, E. G., Lavorova, N. V., Avetisov, V. A., Lunin, V. G. and Naroditskii, B. S. (2000) Genetic engineering of oilseed rape and tomato plants 
expressing a radish defensin gene. Rus. J. Plant Physiol. 47, 417-423.

Penninckx, I. A. M. A., Thomma, B. P. H. J., Buchala, A., Métraux, J. P. and Broekaert, W. F. (1998) Parallel but cooperative activation of jasmonate and ethylene response pathways is required for induction of a plant defensin gene in Arabidopsis. Plant Cell. 10, 2103-2114.

Sambrook, J., Fritsch, E. F. and Maniatis, T. (1989) Molecular Cloning: A Laboratory Manual, 2nd ed., Cold Spring Harbor Laboratory Press, New York, USA.

Spelbrink, R. G., Dilmac, N., Allen, A., Smith, T. J., Shah, D. M. and Hockerman, G. H. (2004) Differential antifungal and calcium channel-blocking activity among structurally related plant defensins. Plant Physiol. 135, 2055-2067.

Terras, F. R., Eggermont, K., Kovaleva, V., Raikhel, N. V., Osborn, R. W., Kester, A., Rees, S. B., Torrekens, S., Van Leuven, F. and Vanderleyden, J. (1995) Small cysteine-rich antifungal proteins from radish: their role in host defense. Plant Cell. 7, 573-588.

Thevissen, K., Ghazi, A., De Samblanx, G. W., Brownlee, C., Osborn, R. W. and Broekaert, W. F. (1996) Fungal membrane responses induced by plant defensins and thionins. J. Biol.
Chem. 271, 15018-15025.

Thevissen, K., Osborn, R. W., Acland, D. P. and Broekaert, W. F. (2000) Specific binding sites for an antifungal plant defensin from dahlia (Dahlia merckii) on fungal cells are required for antifungal activity. Mol. Plant-Microbe Interact. 13, 54-61.

Thevissen, K., Warnecke, D. C., François, I. E. J. A., Leipelt, M., Heinz, E., Ott, C., Zähringer, U., Thomma, B. P. H. J., Ferket, K. K. A. and Cammue, B. P. A. (2004) Defensins from insects and plants interact with fungal glucosylceramides. J. Biol. Chem. 279, 3900-3905.

Wang, Y., Nowak, G., Culley, D., Hadwiger, L. A. and Fristensky, B. (1999) Constitutive expression of a pea defense gene DRR206 confers resistance to blackleg (Leptosphaeria maculans ) disease in transgenic canola (Brassica napus). Mol. Plant-Microbe Interact. 12, 410-418.

Wijaya, R., Neumann, G. M., Condron, R., Hughes, A. B. and Polya, G. M. (2000) Defense proteins from seed of Cassia fistula include a lipid transfer protein homologue and a protease inhibitory plant defensin. Plant Sci, 159, 243-255.

Zhang, N. Y., Jones, B. L. and Tao, P. (1997) Purification and characterization of a new class of insect $\alpha$-amylase inhibitors from barley. Cereal Chem. 74, 119-122. 